\title{
Regio-orientation in condensation of aminopyrazoles with 1,3-difunctional reagents: synthesis of new pyrazolo[1,5- a]pyrimidines; pyrazolo[3,4-d]pyridazines and 2,4-dihydropyrano[2,3-c]pyrazoles
}

\author{
Ayat Elkholy, ${ }^{\text {a }}$ Fawzia Al-Qalaf, ${ }^{b}$ and Mohamed Hilmy Elnagdic* \\ ${ }^{a}$ Department of Chemistry, Faculty of Science, Cairo University, Giza-12613- Egypt \\ ${ }^{b}$ Applied Science Department, College of Technological Studies, Public Authority for Applied \\ Education and Training, Kuwait \\ ${ }^{c}$ Chemistry Department, Kuwait University, P.O. Box 5969; Safat 13060, Kuwait \\ E-mail: shelmy1941@yahoo.com
}

\begin{abstract}
Pyrazolo[1,5-a]pyrimidine derivatives were prepared by condensation of 4-phenyldiazenyl-1Hpyrazole-3,5-diamine with enaminonitriles and with enaminones. The regioorientation of reagents was determined by $\left({ }^{15} \mathrm{~N}\right.$ HMBC) measurements as well as NOE difference experiments. A new one-pot synthesis of pyrazolo[3,4- $d$ ]pyridazines involving the coupling of $N 1$-[4-cyano5(3)-(cyanomethyl)-1H-3(5)pyrazoly]acetamide with benzenediazonium chloride is reported. Synthesis of 2,4-dihydropyrano[2,3-c]pyrazole is also reported.
\end{abstract}

Keywords: Condensed pyrazoles, enaminonitrile, enaminone, ${ }^{15} \mathrm{~N}$ HMBC measurements and NOE difference experiments

\section{Introduction}

The considerable biological and medicinal activities of condensed pyrazoles initiated considerable recent interest in the development of syntheses of these molecules. ${ }^{1-3}$ Condensed pyrazoles are generally obtained by combining aminopyrazoles or pyrazolones with 1,3bifunctional reagents. ${ }^{4-11}$ Over the past two decades, several syntheses of condensed pyrazoles in this way were reported. However, this work does not, in light of the limited availability of modern properly spectroscopic techniques, address definite proof for reported regioorientation or predominance of a tautomer. This article reports syntheses of various substituted condensed azoles from combining aminopyrazoles and pyrazolones with $\alpha, \beta$-unsaturated nitriles, and defines through ${ }^{15} \mathrm{~N}$ HMBC and NOE experiments, the exact structure of products. 


\section{Results and Discussion}

4-Phenyldiazenyl- $1 H$-pyrazole-3,5-diamine 1, was prepared utilizing the procedure originally reported by Elnagdi et al. ${ }^{12}$ This was condensed with 3-piperidino-2-propenenitrile 2, prepared following our recently reported procedure, ${ }^{13}$ to yield a product of addition and piperidine elimination, followed by cyclization and hydrolysis under the reaction conditions. This product could thus be formulated as 4,7-dihydropyrazolo[1,5-a]pyrimidin-7-one 5 or isomeric 4,5dihydropyrazolo[1,5- $a$ ] pyrimidin-5-one 6. This transformation could proceed by two possible mechanisms as shown in Scheme 1. Condensation of 4-phenyldiazenyl-1H-pyrazole-3,5-diamine 1 with 3-piperidino-2-propenenitrile 2 at the ring nitrogen might produce 4 , which in turn, could cyclize to the 4,5-dihydropyrazolo[1,5-a]pyrimidin-5-one $\mathbf{6}$. On the other hand if initial condensation involved the exocyclic amino function, then $\mathbf{3}$ would be produced which could cyclize subsequently to the isomeric 4,7-dihydropyrazolo[1,5-a]pyrimidin-7-one 5. A similar dichotomy is also encountered in cyanoethylation of pyrazole-3,5-diamine $\mathbf{1}$ and was resolved via development of an alternative unambiguous synthesis. ${ }^{14}$ In the present study, NOE difference experiments unambiguously solved this problem since irradiating $\mathrm{NH}$ at $\delta_{\mathrm{H}}=8.86 \mathrm{ppm}$ enhanced the pyrimidine ring proton at $\delta_{\mathrm{H}}=8.16 \mathrm{ppm}$, establishing the structure as 4,7dihydropyrazolo[1,5-a]pyrimidin-7-one $\mathbf{5}$.

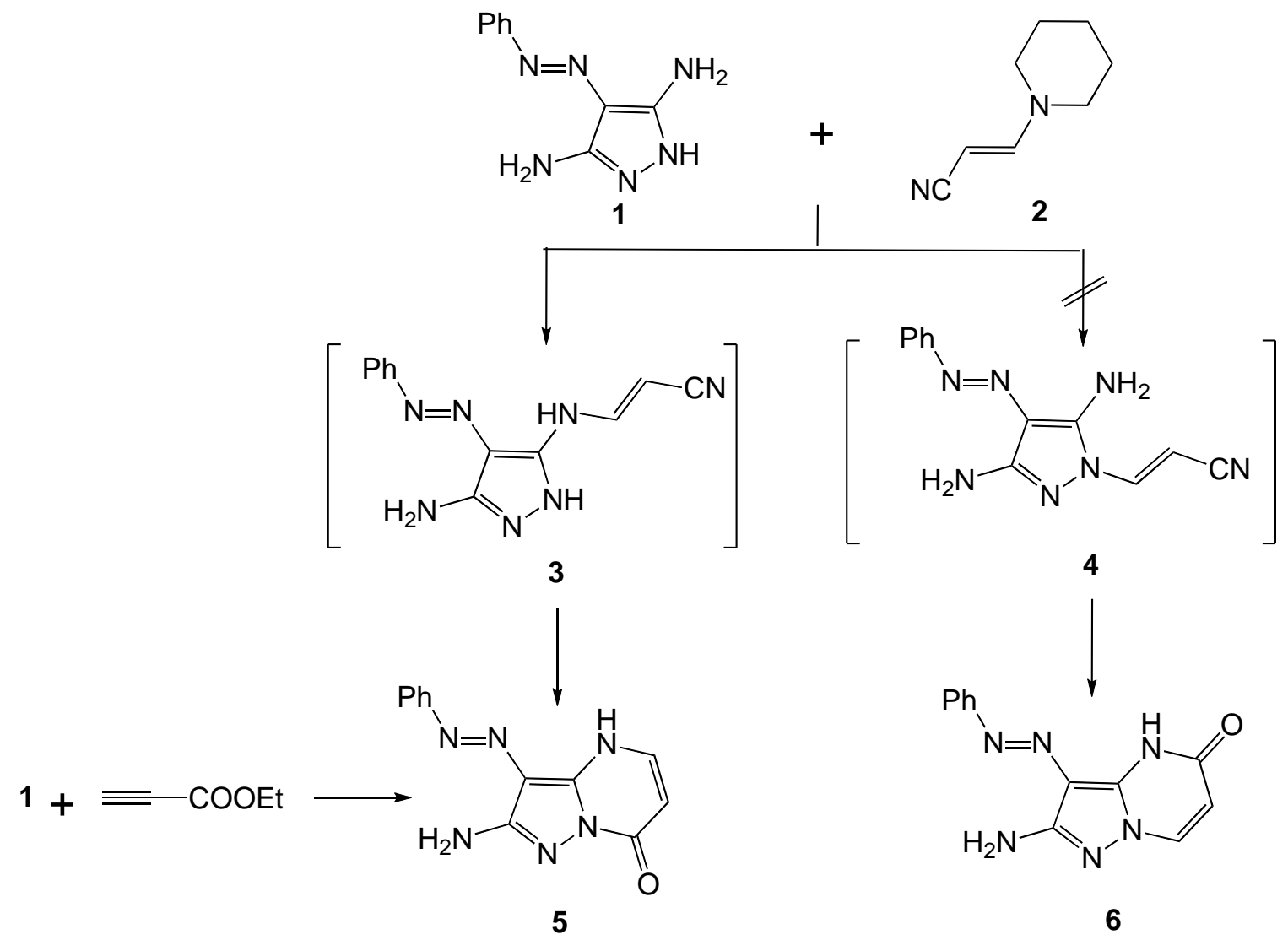

Scheme 1 
Moreover, and in line with the previous reports, the IR spectrum of the product of reaction showed a peak at $1672 \mathrm{~cm}^{-1}$ for the carbonyl function at C-7 (cf. Scheme 1). ${ }^{1} \mathrm{H}$ NMR analysis showed two doublets at $\delta_{\mathrm{H}} 8.16$ and $6.54 \mathrm{ppm}, J=7.0 \mathrm{~Hz}$, for $\mathrm{H}-5$ and H-6 respectively, along with the aryl and the amino protons. As expected, compound 5 was also obtained upon long reflux of 4-phenyldiazenyl-1 $H$-pyrazole-3,5-diamine 1 with ethyl propiolate in pyridine.

The reaction of 4-phenyldiazenyl- $1 H$-pyrazole-3,5-diamine 1 with 3-(dimethylamino)-1-(2naphthyl)-2-propen-1-one 7 yielded a product of condensation that could be 7-(2-naphthyl)-3(2phenyl-1-diazenyl)pyrazolo[1,5-a]pyrimidin-2-amine $\mathbf{8}$ or isomeric 5-(2-naphthyl)-3-[(E)-2phenyl-1-diazenyl]pyrazolo[1,5-a]pyrimidin-2-amine 9 depending on the site at which initial attack occurred (cf. Scheme 2). HMBC- ${ }^{15} \mathrm{~N}$ spectra established structure 9 for the product. The major discrepancy between these two structures is the crosspeak correlation ${ }^{3} J$ observed between the downfield proton at $\delta_{\mathrm{H}}=8.64 \mathrm{ppm}$ with $\mathrm{N}-1$ at $\delta_{\mathrm{N}}=276 \mathrm{ppm}$. The existence of this correlation excludes structure 8 in which the downfield proton is at position 5. Other correlations between this proton at $\delta_{\mathrm{H}}=8.64 \mathrm{ppm}$ with N-4 at $\delta_{\mathrm{N}}=230 \mathrm{ppm}{ }^{4} J$ and with N-7a at $\delta_{\mathrm{N}}=215$ ppm ${ }^{2} J$ were observed. The correlations observed between the upfield proton H-6 at $\delta_{\mathrm{H}}=7.40$ ppm with N-7a, N-4 and N-1 at $\delta_{\mathrm{N}}=215,230$ and $276 \mathrm{ppm}$ are also consistent with the structure.

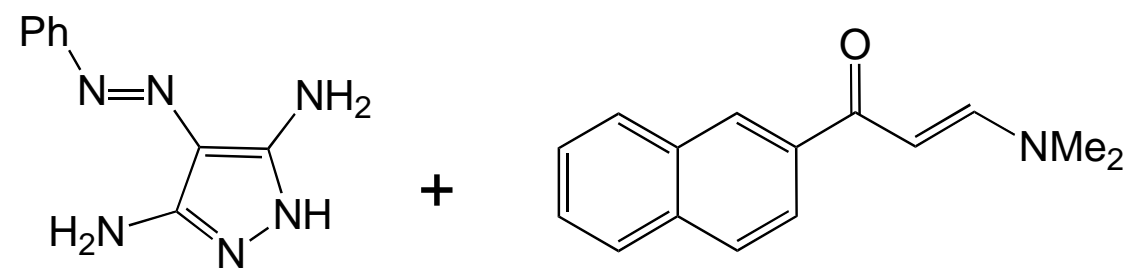

1

7

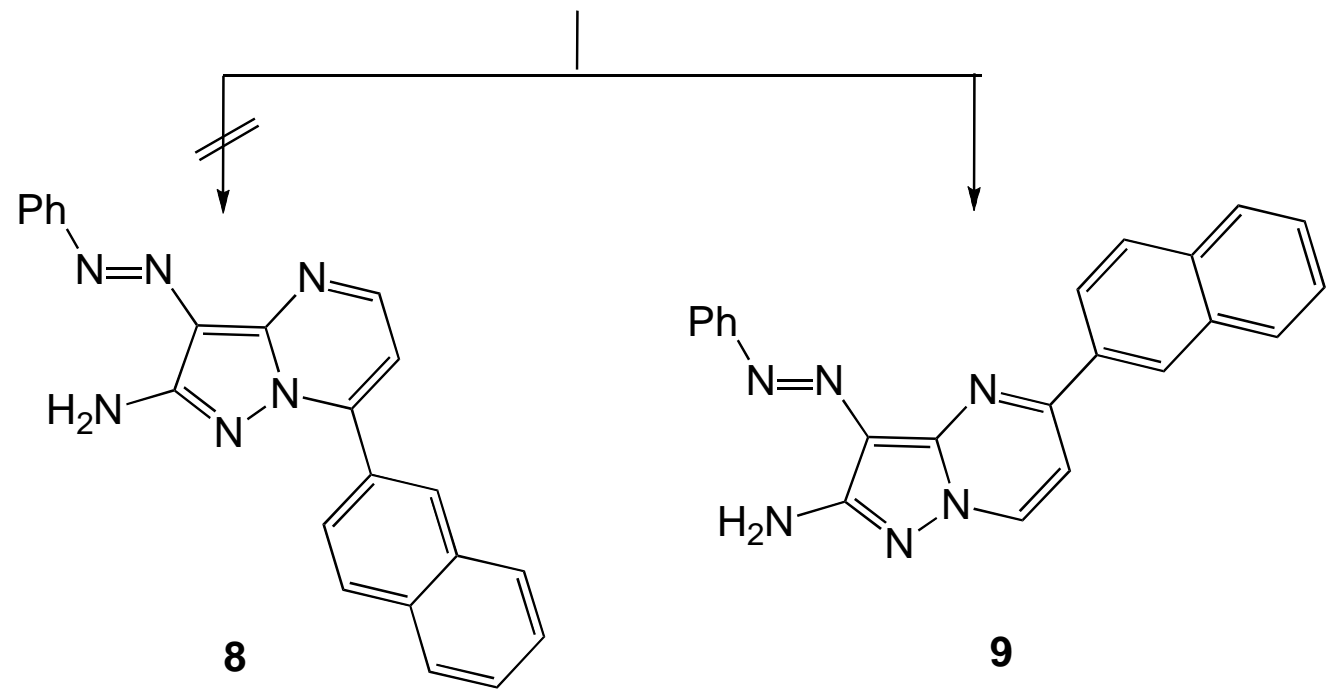

\section{Scheme 2}

The 5-Amino-3-cyanomethyl-1H-pyrazole-4-carbonitrile $\mathbf{1 0}$ was prepared following the procedure described by Taylor and Hartke. ${ }^{15}$ This compound when acylated with acetic 
anhydride, afforded the 5(3)-(pyrazolyl)acetamide derivative 11 in 90\% yield. Coupling 11 with benzenediazonium chloride afforded the (pyrazolo[3,4- $d]$ pyridazin-3-yl)acetamide derivative 14, most likely via 12-13. The ${ }^{1} \mathrm{H}$ NMR of both 11 and 14 revealed the existence of a tautomeric equilibrium mixture of 11a-b and 15a-b (Experimental section) (cf. scheme 3). Pyrazolo[3,4d] pyridazine derivatives have recently been shown to be useful inhibitors of PDE-5 and are suggested as peripheral vasodilators. ${ }^{16}$<smiles>N#CCc1n[nH]c(CC(=O)O)c1C#N</smiles>

10<smiles>CNc1[nH]nc(CC#N)c1C#N</smiles>

$11 a$<smiles>CC=CCc1[nH]nc(NC=O)c1C#N</smiles>

$11 b$

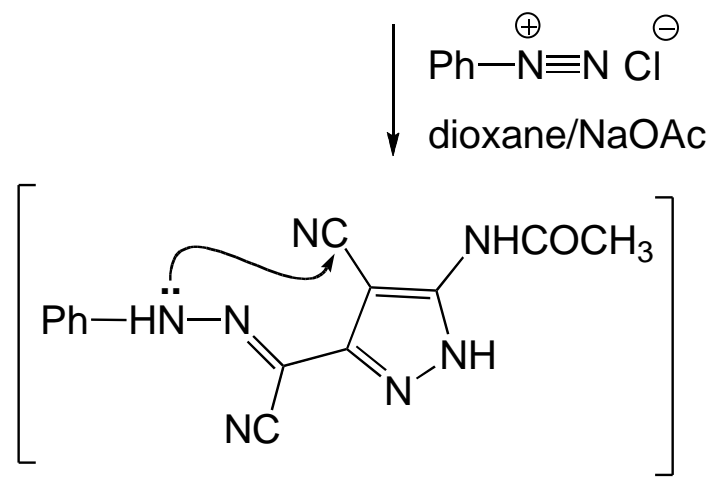

12<smiles>CC(=O)Nc1n[nH]c2c(C#N)nn(-c3ccccc3)c(=O)c12</smiles>

$14 b$<smiles>CNc1[nH]nc2c(C#N)nn(-c3ccccc3)c(=O)c12</smiles>

$14 a$<smiles>CC(=O)Nc1[nH]nc2c(C)nn(-c3ccccc3)c(=N)c12</smiles>

13

\section{Scheme 3}

The reaction of 3-methyl-1H-pyrazol-5(4H)-one 15 with benzylidenemalononitrile has long been reported to yield 1,4-dihydropyrano[2,3-c]pyrazoles. In the present investigation, the pyrazolone 15 was reacted with benzylidenemalononitrile to yield 6-amino-3-ethyl-4-phenyl- 
(1)2,4-dihydropyrano[2,3-c]pyrazole-5-carbonitrile 17, which existed predominantly, at least in DMSO, as the 2,4-dihydro tautomer 17b (cf. Scheme 4). This was shown by NOE difference experiments via irradiation of $\mathrm{NH}$ at $\delta_{\mathrm{H}}=12.14 \mathrm{ppm}$ that enhanced the methylene protons at $\delta_{\mathrm{H}}=$ 2.16 and $0.77 \mathrm{ppm}$. Similar behavior has been reported for 2,4-dihydrotautomer. ${ }^{18}$

In conclusion, it has been found that the syntheses of condensed pyrazoles via reaction of aminopyrazoles with bidentate reagents are very efficient, furthermore, NOE difference experiments and $\mathrm{HMBC}-{ }^{15} \mathrm{~N}$ spectra can be utilized effectively to establish, with certainty, the structures of the products of the reactions.

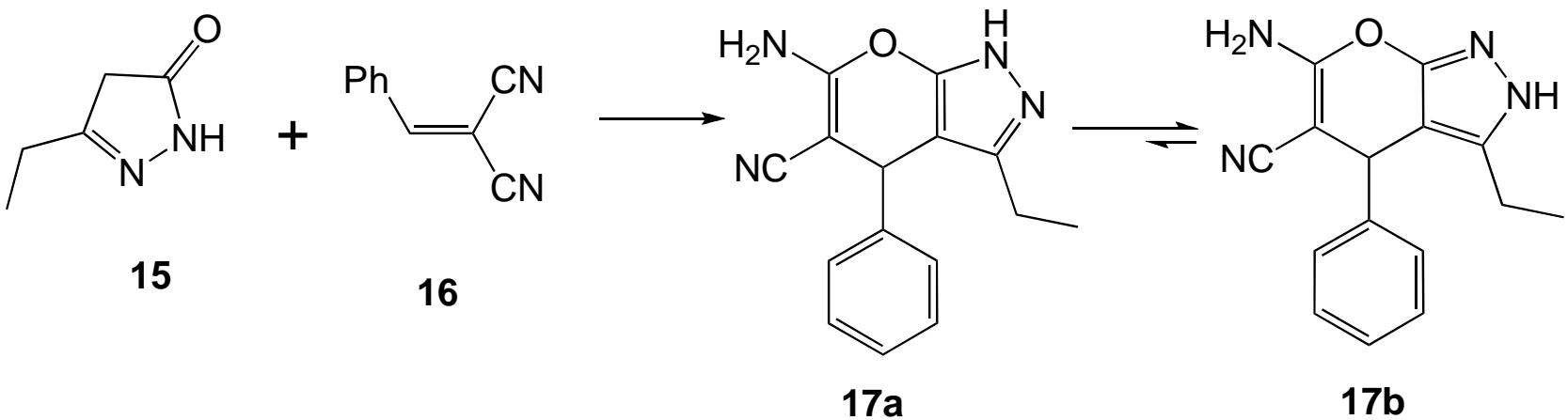

Scheme 4

\section{Experimental Section}

General Procedures. Melting points were determined on a Shimadzu-Gallenkamp apparatus and are uncorrected. Elemental analyses were obtained by means of a LECO CHNS-932 Elemental Analyzer. NMR spectra were measured using a Bruker DPX $400 \mathrm{MHz}$ superconducting spectrometer, HMQC, DEPT and NOE spectra were measured using Bruker Avance II $600 \mathrm{MHz}$ superconducting spectrometer, and FT-IR measurements were from a Perkin Elmer 2000 FT-IR system. Mass spectrometric analysis was carried out on a VG-Autospec-Q high performance tri-sector GC/MS/MS.

\section{2-Amino-3-(2-phenyl-1-diazenyl)-4,7-dihydropyrazolo[1,5-a]pyrimidin-7-one 5}

A mixture of 4-phenyldiazenyl-1 $H$-pyrazole-3,5-diamine 1 ( $1.47 \mathrm{~g}, 10 \mathrm{mmol})$ and 3-piperidino2-propenenitrile $(1.36 \mathrm{~g}, 10 \mathrm{mmol})$ in pyridine $(10 \mathrm{ml})$ was refluxed for $3 \mathrm{~h}$. The reaction mixture was reduced to one-third of its volume then acidified with $\mathrm{HCl}(5 \mathrm{ml}, 10 \%)$. The separated crystals were collected and crystallized from dioxane. Yield $=1.82 \mathrm{~g}(72 \%) . \mathrm{mp} 200-202{ }^{\circ} \mathrm{C}$. IR $(\mathrm{KBr}): 3396\left(\mathrm{NH}_{2}\right), 3029(\mathrm{NH}), 1672 \mathrm{~cm}^{-1}(\mathrm{CO}) ; \mathrm{MS} \mathrm{m} / z\left(\mathrm{M}^{+}-1\right)=253 ;{ }^{1} \mathrm{H}$ NMR (DMSO- $\left.d_{6}\right): \delta$ $=6.54(\mathrm{~d}, 1 \mathrm{H}, J=7.0 \mathrm{~Hz}, \mathrm{H}-6), 7.20$ (br. s, $2 \mathrm{H}, \mathrm{NH}_{2}, \mathrm{D}_{2} \mathrm{O}$ exchangeable), 7.41 (t, 1H, phenyl $\mathrm{H}), 7.53(\mathrm{t}, 2 \mathrm{H}, J=7.3 \mathrm{~Hz}$, phenyl H), $7.93(\mathrm{~d}, 2 \mathrm{H}, J=7.2 \mathrm{~Hz}$, phenyl H), $8.16(\mathrm{~d}, 1 \mathrm{H}, J=7.0$ $\mathrm{Hz}, \mathrm{H}-5)$. Anal. Calcd for $\mathrm{C}_{12} \mathrm{H}_{10} \mathrm{~N}_{6} \mathrm{O}$ : (254.25): C, 56.69; H, 3.96; N, 33.05\% Found: C, 56.88; $\mathrm{H}, 4.25 ; \mathrm{N}, 33.12 \%$ 


\section{5-(2-Naphthyl)-3-(2-phenyl-1-diazenyl)pyrazolo[1,5-a]pyrimidin-2-amine (9)}

A mixture of 4-phenyldiazenyl-1H-pyrazole-3,5-diamine 1 (1.47 g, $10 \mathrm{mmol})$ and 3(dimethylamino)-1-(2-naphthyl)-2-propen-1-one $7(2.25 \mathrm{~g}, 10 \mathrm{mmol})$ in pyridine $(10 \mathrm{ml})$ was refluxed for $3 \mathrm{~h}$. The reaction mixture was reduced to one-third of its volume, then acidified with $\mathrm{HCl}(10 \mathrm{ml}, 10 \%)$. The separated crystals were collected and recrystallized from EtOH. Yield = $3.24 \mathrm{~g}(89 \%) . \mathrm{mp}>300{ }^{\circ} \mathrm{C}$. IR (KBr): 3217 and $3164 \mathrm{~cm}^{-1}\left(\mathrm{NH}_{2}\right)$; $\mathrm{MS} m / z(\mathrm{M})^{+}=364$.; ${ }^{1} \mathrm{H} \mathrm{NMR}$ (DMSO- $d_{6}$ ): $\delta=7.28$ (br. s, $2 \mathrm{H}, \mathrm{NH}_{2}, \mathrm{D}_{2} \mathrm{O}$ exchangeable), 7.35 (t, $1 \mathrm{H}, J=7.2 \mathrm{~Hz}$, arom. H), 7.40 (d, 1H, $\left.J=4.8 \mathrm{~Hz}_{2} \mathrm{H}-6\right), 7.49$ (t, 2H, $J=7.2 \mathrm{~Hz}$, arom. H), 7.61-7.68 (m, 2H, arom. H), $7.83(\mathrm{~d}, 2 \mathrm{H}, J=7.2 \mathrm{~Hz}$, arom. H), 8.03 (d, 1H, $J=8.4 \mathrm{~Hz}$, arom. H), 8.07 (d, 1H, $J=8.4 \mathrm{~Hz}$, arom. H), 8.10-8.15 (m, 2H, arom. H), 8.65 (d, $1 \mathrm{H}, J=4.8 \mathrm{~Hz}, \mathrm{H}-5), 8.70$ (d, 1H, $J=8.4 \mathrm{~Hz}$, arom. H). Anal. Calcd for $\mathrm{C}_{22} \mathrm{H}_{16} \mathrm{~N}_{6}$ : (364.40): C, 72.51; H, 4.43; N, 23.06\% Found: C, 72.68; H, $4.50 ; \mathrm{N}, 23.00 \%$

\section{N1-[4-Cyano-3(5)-(cyanomethyl)-1H-5(3)-pyrazolyl]acetamide (11)}

5-Amino-3-cyanomethyl-1H-pyrazole-4-carbonitrile 10 (1.47 g, $10 \mathrm{mmol})$ was heated at reflux in $\mathrm{Ac}_{2} \mathrm{O}(10 \mathrm{ml})$ for a period of $1 \mathrm{~h}$. The solvent was removed by distillation under reduced pressure to obtain the crude product that was crystallized from ethanol. Yield $=1.70 \mathrm{~g}(90 \%)$. $\mathrm{mp}$ 198-200 ${ }^{\circ} \mathrm{C}$. IR (KBr): 3309 and $3235(2 \mathrm{NH}), 2222(\mathrm{CN})$ and $1717 \mathrm{~cm}^{-1}(\mathrm{CO})$; MS m/z $\left(\mathrm{M}^{+}-1\right)=$ 188; ${ }^{1} \mathrm{H}$ NMR (DMSO- $\left.d_{6}\right): \delta=2.12\left(\mathrm{~s}, 3 \mathrm{H}, \mathrm{COCH}_{3}\right), 4.14\left(\mathrm{~s}, 2 \mathrm{H}, \mathrm{CH}_{2}\right), 8.07$ (br. s, $1 \mathrm{H}, \mathrm{NH}$, $\mathrm{D}_{2} \mathrm{O}$ exchangeable), 11.30 (br. s, $1 / 2 \mathrm{H}, \mathrm{NH}, \mathrm{D}_{2} \mathrm{O}$ exchangeable), 13.46 (br. s, $1 / 2 \mathrm{H}, \mathrm{NH}, \mathrm{D}_{2} \mathrm{O}$ exchangeable). Anal. Calcd for $\mathrm{C}_{8} \mathrm{H}_{7} \mathrm{~N}_{5} \mathrm{O}$ : (189.17): C, 50.79; H, 3.73; N, 37.02\% Found: C, $50.83 ; \mathrm{H}, 3.58 ; \mathrm{N}, 37.24 \%$

\section{N1-(7-Cyano-4-oxo-5-phenyl-4,5-dihydro-2(1)H-pyrazolo[3,4-d]pyridazin-3-yl)acetamide}

(14) a A prepared solution of benzenediazonium chloride $(10 \mathrm{mmol})$ was added dropwise to a cold solution of pyrazoloacetamide $11(10 \mathrm{mmol})$ in dioxane $(15 \mathrm{ml})$ and a solution of sodium acetate $(15 \mathrm{mmol})$ in water $(10 \mathrm{ml})$. The mixture was stirred for a period of $1 \mathrm{~h}$, then allowed to warm up to rt. During this time a precipitate was formed. The product was filtered off and recrystallized from acetic acid. yield $(83 \%, 2.20 \mathrm{~g}) ; \mathrm{mp} 250{ }^{\circ} \mathrm{C}$. IR (KBr): 3389 and $3244\left(\mathrm{NH}_{2}\right)$, 3171(NH), $\mathrm{cm}^{-1} 2185(\mathrm{CN})$; MS $m / z\left(\mathrm{M}^{+}-1\right)=265$; ${ }^{1} \mathrm{H}$ NMR (DMSO-d6): $\delta=2.19(\mathrm{~s}, 3 \mathrm{H}$, $\left.\mathrm{COCH}_{3}\right), 7.29-7.36(\mathrm{~m}, 2 \mathrm{H}$, phenyl-H), 7.53 (d, 2H, $J=7.4 \mathrm{~Hz}$, phenyl-H), 7.69 (t, $1 \mathrm{H}, J=7.4$ $\mathrm{Hz}$, phenyl-H), 11.34 (br. s, $1 / 2 \mathrm{H}, \mathrm{NH}, \mathrm{D}_{2} \mathrm{O}$ exchangeable), 11.57 (br. s, $1 \mathrm{H}, \mathrm{NH}, \mathrm{D}_{2} \mathrm{O}$ exchangeable). 13.70 (br. s, $1 / 2 \mathrm{H}, \mathrm{NH}, \mathrm{D}_{2} \mathrm{O}$ exchangeable). Anal. Calcd for $\mathrm{C}_{14} \mathrm{H}_{10} \mathrm{~N}_{6} \mathrm{O}_{2}$ : (294.27): C, 57.14; H, 3.43; N, 28.56\% Found: C, 57.07; H, 3.55; N, 28.79\% 


\section{6-Amino-3-ethyl-4-phenyl-2,4-dihydropyrano[2,3-c]pyrazole-5-carbonitrile (17b)}

A mixture of 3-ethyl-4,5-dihydro-1H-5-pyrazolone $15 \quad(1.12 \mathrm{~g}, 10 \mathrm{mmol})$ and benzylidenemalononitrile $16(1.54 \mathrm{~g}, 10 \mathrm{mmol})$ in $\mathrm{EtOH}(10 \mathrm{ml})$, in the presence of a few drops of piperidine, was refluxed for a period of $3 \mathrm{~h}$. The reaction mixture was then reduced to onethird of its volume, after which it was acidified with $\mathrm{HCl}(5 \mathrm{ml}, 10 \%)$. The separated crystals were collected by suction and crystallized from EtOH. Yield $=2.18 \mathrm{~g}(82 \%) . \mathrm{mp} 118-200{ }^{\circ} \mathrm{C}$. IR (KBr): 3424 and $3398\left(\mathrm{NH}_{2}\right)$, and $3171(\mathrm{NH}), 2185 \mathrm{~cm}^{-1}(\mathrm{CN}) ; \mathrm{MS} \mathrm{m} / \mathrm{z}\left(\mathrm{M}^{+}\right)=266$; ${ }^{1} \mathrm{H}$ NMR (DMSO-d6): $\delta=0.771\left(\mathrm{t}, 3 \mathrm{H}, J=7.5 \mathrm{~Hz}, \mathrm{CH}_{3}\right), 2.15$ (q, 2H, $\left.J=7.5 \mathrm{~Hz}, \mathrm{CH}_{2}\right), 4.61(\mathrm{~s}, 1 \mathrm{H}$, $\mathrm{CH}), 6.88$ (br. s, 2H, $\mathrm{NH}_{2}, \mathrm{D}_{2} \mathrm{O}$ exchangeable), 7.16-7.20 (m, 2H, phenyl-H), 7.24 (t, $1 \mathrm{H}, J=$ $7.4 \mathrm{~Hz}$, phenyl-H), 7.31 (d, 2H, $J=7.4 \mathrm{~Hz}$, phenyl-H), 12.14 (br. s, $1 \mathrm{H}, \mathrm{NH}, \mathrm{D}_{2} \mathrm{O}$ exchangeable). Anal. Calcd for $\mathrm{C}_{15} \mathrm{H}_{14} \mathrm{~N}_{4} \mathrm{O}$ : (266.30): C, 67.65; H, 5.30; N, 21.04\% Found: C, $67.59 ; \mathrm{H}, 5.32 ; \mathrm{N}, 21.25 \%$

\section{Acknowledgements}

The authors would like to thank the Public Authority for Applied Education and Training for its financial support of this research project (Transform grant TS-06-14).

\section{References and Notes}

1. Dündar, Y; Dodd S.; Strobl J.; Boland A.; Dickson R.; Walley T. Hum. Psychopharmacol. 2004, 19, 305.

2. Kling, J. Mod. Drug Discov. 1998, 1, 31.

3. Pacher, P.; Szabo, N. A. Pharmacol. Rev. 2006, 58, 87.

4. Anwar, H. F.; Fleita, D. H.; Kolshorn, H.; Meier H.; Elnagdi, M. H. ARKIVOC 2006, (xv), 133.

5. Al-Mousawi, S. M.; Moustafa, M. S.; Elnagdi, M. H. Heterocycles 2008, 75, 1371.

6. Elnagdi, M. H.; Elmoghayar, M. R. H.; Elgemeie, G. G. H. Adv. Heterocycl. Chem. 1987, $41,319$.

7. Al-Qalaf, F.; Abdelkhalik, M. M.; Al-Enezi, A.; Al-Ajmi, J. R. Heterocycles 2008, 75, 145.

8. Al-Saleh, B.; AbdelKhalik, M. M.; Al-Enzy, A.; Elnagdi, M. H. J. Chem. Res. 1999 (S), 654, (M), 2848.

9. Ana, M. F.; Oliveira-Campos, Salaheldin, A. M.; Rodrigues L. M. ARKIVOC 2007, (xvi), 92.

10. Jin, T. S.; Zhao, R. Q.; Li, T. S. ARKIVOC 2006, (xi), 176.

11. Shawali, A. S.; Edrees, M. M. ARKIVOC 2006, (ix), 292.

12. Elnagdi M. H.; Abdoula. S. O. J. Prakt. Chem. 1973, 315, 1009. 
13. Makhseed, S.; Hassaneen, H. M. E.; Elnagdi, M. H. Z. Naturforsch., B, Chem. Sci. 2007, 62, 529.

14. Elnagdi, M. H. Tetrahedron 1974, 30, 2791.

15. Taylor, E. C.; Hartke, K. S. J. Amer. Chem. Soc. 1959, 81, 2456.

16. Elnagdi, M. H.; Al-Awadi, N.; Abdelhamid, I. A. Comprehensive Heterocyclic Chemistry III, Elsevier: New York; 2008, Vol. 10. Chap. 12, p 651.

17. Shestopalov, A. M.; Yakubov, A. P.; Tsyganov, D. V.; Emel'yanova, Yu. M.; Nesterov, V. N. Chem. Heterocycl. Compd. (Engl. Transl.) 2002, 38, 1180. 